\section{Obesity Facts}

The European Journal of Obesity

\section{Editorial}

223 The $1 D 1$ of Burning Calories

Müller, T.D.; Chaudhary, N.; Pfluger, P.T.; Tschöp, M. (Cincinnati, OH)

Original Articles

227 A Health Assessment Tool for Multiple Risk Factors for Obesity: Psychometric Testing and Age Differences in UK Adults

Chambers, J.A.; Swanson, V. (Stirling)

237 Overweight and Cardiovascular Risk Factors in 4- to 18-Year-Olds Craig, L.C.A.; Love, J.; Ratcliffe, B.; McNeill, G. (Aberdeen)

243 Measurement of Waist Circumference at Four Different Sites in Children, Adolescents and Young Adults: Concordance and Correlation with Nutritional Status as well as Cardiometabolic Risk Factors Hitze, B.; Bosy-Westphal, A.; Bielfeldt, F.; Settler, U.; Mönig, H.; Müller, M.J. (Kiel)

251 Prevalence of Obesity and Abdominal Obesity in Swedish Primary Care and Occupational Health Clinics

Pettersson, J.; Johansson, K.; Rössner, S.; Neovius, M. (Stockholm)

259 Circulating Markers of Inflammation and Their Link to Indices of Adiposity Browning, L.M.; Krebs, J.D.; Magee, E.C. (Cambridge); Frühbeck, G. (Pamplona); Jebb, S.A. (Cambridge)

266 Influence of Partial Sleep Deprivation on Energy Balance and Insulin Sensitivity in Healthy Women

Bosy-Westphal, A.; Hinrichs, S.; Jauch-Chara, K.; Hitze, B.; Later, W.; Wilms, B.; Settler, U. (Kiel); Peters, A. (Lübeck); Kiosz, D.; Müller, M.J. (Kiel)

274 Influence of Calcium and Vitamin D Supplementation on Weight and Fat Loss in Obese Women

Holecki, M.; Zahorska-Markiewz, B.; Wieçek, A.; Mizia-Stec, K.; Nieszporek, T.; Zak-Golab, A. (Kattowice)

281 Meetings and Conferences

282 Imprint

283 Guidelines for Authors

284 Contents of Forthcoming Issues 